\title{
Research on Adopting Application in Agricultural Products Supply Chain Based on Internet of Things
}

\author{
Jian Zhao ${ }^{1}$ and Xiaoming Dong ${ }^{2, *}$ \\ ${ }^{1}$ College of Economics and Management, Northeast Agricultural University, Harbin, 150030, China; ${ }^{2}$ School of Com- \\ puter \& Information, Anqing Teachers College, Anqing, 246011, China
}

\begin{abstract}
With the further deepening of the developing economy, China's agriculture will face a huge crisis. Under the impact of global competition, our country agriculture showed a low level of industrialization, the low level of management, the value chain of low level and low degree of information technology. Organizational decentralization and shortcomings are lack of food quality and safety. In this paper, through the supply chain of agricultural products in the internet of things technology, the overall framework for establishing network analysis technology application of business process of the supply chain of agricultural products in the application mode, to sort out the various links of production. In the supply chain of agricultural products processing, storage, transportation and sales; through the proposed strategy layer, the implementation of three layer and support layer network hierarchical structure of agricultural products supply chain management system, the management system of existing network system and agricultural products in the supply chain (ERP, MIS, CRM) to the organic integration, and the supply chain strategy and daily operation planning and supply chain management system together, so that the whole agricultural product supply chain has become a highly efficient, reasonable overall.
\end{abstract}

Keywords: Agricultural means of production, internet of things, supply chain, TOE model.

\section{INTRODUCTION}

In the background of the global economic development, continuous integration of the global economy, the supply chain of agricultural products in China are confronted with the fierce competition of agricultural products [1]. For the enterprises, to survive in such a fierce competition environment down, we must constantly change, innovation, to improve the efficiency of enterprises using advanced technologies [2]; at the same time, in recent years, the safety problems of agricultural products emerge in an endless stream, the people are also getting to the safety problems of agricultural products is concerned, the Chinese government is also on the food safety issue of great concern, China's government is waging a campaign for food safety problems [3-5].

In recent years, the business system of China has investigated tens of thousands of cases of fake cultural materials including many kilograms of substandard seeds and many kilograms of substandard fertilizer. These fake agricultural products will bring enormous loss to the farmers. In China, one of the important reasons why we cannot eliminate the problem of fake and shoddy agricultural products is that China has not established a reasonable sound agricultural supply chain [6]. Existing agricultural supply chain has disadvantages in decentralized management and lack of convergence. It is the technology of internet of things that solves the above problem by providing a feasible and efficient solution [7]. In our current environment, the internet of things, with its real-time, accurate and shared characteristics, will bring great changes to the agricultural supply chain and will provide a critical technology for establishing a smooth flow of agricultural logistics and supply chain information [8].

This paper focuses on foreign technology adoption theory and factors are summarized, it provides a theoretical basis for the Internet of things technology adoption. At the same time, the research of this paper enriches the theory of research adopted domestic technology. This paper presents the agricultural products supply chain management technology of Internet of things based on three layer framework (strategic layer, execution layer, support layer). In the agricultural information processing and application infrastructure, application of facility agriculture IOT is mainly embodied in the realization of intelligent agricultural production, management, decision-making, therefore on the agricultural production of the key link, need to focus on the applications of the Internet of things technology in crop growth data processing facilities, production of digital management, data sharing, user interface and service intelligent network, intelligent decision-making.

\section{RELATED BASIC THEORY}

\subsection{Research Status of Agricultural Products Supply Chain}

The domestic and international research about the supply chain of agricultural products mainly focus on quality and 
safety, risk management, supply chain organization efficiency, information technology application (RFID tracing application), supply chain evaluation and so on several aspects [9]. Study on the supply chain of agricultural products in foreign countries is mainly the information management and the quality and safety aspects analysis, supply chain in the supply chain value. Development of Hofman [10] and points out the fishery supply chain cannot do without the information and communications technology, the overall competitiveness of the use of information and communication technology can greatly improve the fishery supply chain. Curieux-Belfond [11] pointed out that the professional standards of aquatic products processing is very important to ensure the quality and safety of aquatic products, shall establish professional standards and continuous improvement.

The domestic research literature about agricultural products supply chain mainly concentrated in a few quality safety, risk management, organization efficiency etc. Han Limin and Deng Yunfeng pointed out that China's fishery industry there are farming, fishing, and aquatic products processing three industrial values. Jin Shufang and each part of the application of RFID technology to the aquatic product supply chain production, processing, storage, transportation, sales, and the need to solve the problem in the application described [8].

\subsection{Internet of Things Theory}

Acquisition sub layer integrated bar code, sensors, satellite positioning, RFID and multimedia information acquisition technology data acquisition, access to a variety of data information of all kinds of voice, video and other multimedia data, physical quantity, marking the physical world. Selforganizing sensor network digital link coding, modulation, and demodulation technology is based on data transmission, to realize sensor and sensor nodes in the LAN between, networking, traffic management, routing technology based on self interaction, organization and coordination among the nodes.

When the complete data collection, in order to effectively reduce the data redundancy, improve the quality of data, also need, data fusion, compression, clustering, recognition and other information processing technology to the original coordinate sensing data processing based on.

In a unit of time, occurrence of foot data communication between $n$ computers $(1 \leqq Y \leqq n / 2)$, source machine to the destination machine communication and participation are random, uniformly distributed in $\mathrm{n}$;

From the moment of into the system of $n, n$ machines as a poison, its number is $\mathrm{Cl}$; a computer $\mathrm{Di}(\mathrm{i} \neq 1)$ virus conditions are: $\langle\mathrm{Di}, \mathrm{Dj}>\in \mathrm{Ec}, \mathrm{I}(\mathrm{Di} \in \mathrm{GY}) \mathrm{I}(\mathrm{Dj} \in \mathrm{GY})$; the computer once infected with the virus, the epidemic is poison machine. Let Xn be the number of infected computers, in the first $\mathrm{n}$ unit time in $\mathrm{D}\{\mathrm{Xn}, \mathrm{n} \geqq 1\}$ constitutes a discrete random process, in the $\mathrm{Z}$ units of time, the number of infected machines is $\mathrm{E}(\mathrm{Xi})$, it is not the number of exposure machine as $(\mathrm{Z}-\mathrm{E}(\mathrm{Xi}))$. Foot data communication in the $\mathrm{Z}$ units of time and the $n+1$ units of time intervals, expected exposure machine mathematics source machine value:
$\frac{Y}{Z}=E\left(X_{i}\right)$

Mathematical expectation of the number of non-toxic machine target values:

$Y-\frac{Y}{Z} E\left(X_{i}\right)$

$\frac{Y}{Z} E\left(X_{i}\right)\left(1-\frac{E\left(X_{i}\right)}{N Z}\right)$

$E\left(X_{i+1}\right)-E\left(X_{i}\right)=\frac{Y}{Z} E\left(X_{i}\right)\left(1-\frac{E\left(X_{i}\right)}{Z}\right)$

$\frac{E\left(X_{i+1}\right)-E\left(X_{i}\right)}{(i+1)-i}=\frac{Y}{Z} E\left(X_{i}\right)\left(1-\frac{E\left(X_{i}\right)}{Z}\right)$

According to the random assumption and propagation, new mathematical expectation for exposure machine is shown as follow:

In the number of exposure machine is shown as follows:

The number of units of time for exposure machine is shown:

Separation of variables, the solution and discrete time $n$, exposure to the computer number:

$$
E\left(X_{i}\right)=\frac{Z}{\left[1+(Z-1) e^{-\frac{i Y}{Z}}\right]}
$$

\subsection{The Key Technology of Internet of Things}

Formal due to RFID with these advantages, RFID has been applied to many fields, that create great value for society. In recent years, as the Chinese government policy to promote, the application of RFID in the field of our country has been very extensive, RFID in the electronic ticket, highway automatic toll collection, railway automatic train identification, food safety, supply chain management and many other application fields have many mature case. The Radio Frequency Identification (RFID) is a non-contact automatic identification technology and obtains relevant data by automatically identifying the label on the objects. It is one of the most critical technologies in the technologies of internet of things.

The technology of network communication includes a variety of wired and wireless transmission technology, switching technology, network technology and gateway technology, which is the basis of perceiving and communicating information between objects. The Cloud Computing is the product that combine traditional computer technology with network technology including grid computing, parallel computing, distributed computing, utility computing, virtualization, network storage, load balancing and other traditional computer technology and network technology. Sensor is based on accuracy and some rules are to be measured easily to identify the relationship between, a physical quantity measuring device and application. 


\subsection{Technology, Organization, Environment Analysis Framework (TOE)}

Tornatzky is the critical theory of classical diffusion of innovation, factors that influence the diffusion of information technologies not only contains the characteristic elements of the technology itself (T), also contains the organization characteristic elements $(\mathrm{O})$, environmental factor $(\mathrm{E})$. The TOE framework is proposed, because of its wide applicability, many scholars at home and abroad based on TOE framework is studied, also studied the factors contained in this framework. The technical characteristics of the characteristics of technology itself, including technical compatibility, complexity, organizational factors include the size of the organization, high-level support, organizational culture, the environmental factors include external competition pressure, the government policy support. The TOE framework was shown in Fig. (1).

\section{ANALYSIS OF AGRICULTURAL SUPPLY CHAIN BASED ON THE INTERNET OF THINGS}

\subsection{The Architecture System of the Internet of Things for Agricultural Supply Chain}

This paper argues that the system architecture of the Internet of Things for agricultural supply chain can also be divided into three layers including the layer of perception, the layer of network and the layer of application. It is shown in Fig. (2).

The layer of perception in the internet of things for agricultural supply chain contains the tag EPC, mobile reader RFID, sensor network and other sensing devices. In this layer, we should focus on solving the problem of perceiving and recognizing objects and collecting information. The main technology in this layer involves the technology of RFID, sensing, control and short-rang wireless communication. The information on tag EPC of agricultural products will be collected by RFID. Then it will be sent to the next layer, the layer of network.

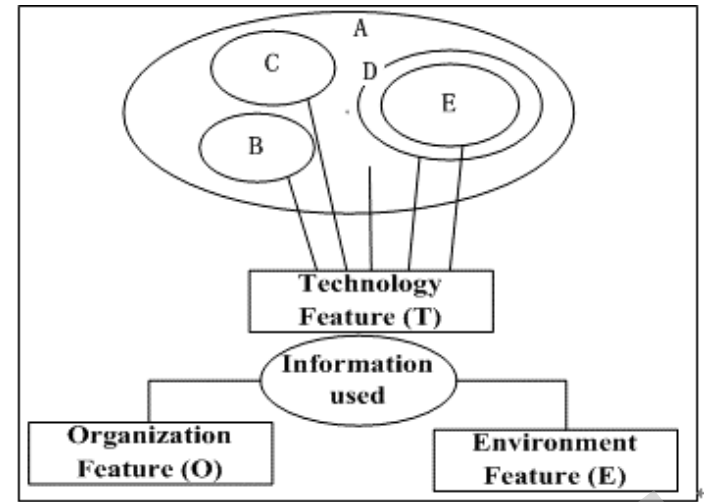

Fig. (1). TOE framework.

\subsection{Analysis of Internet of Things for Agricultural Sup- ply Chain}

In the traditional agricultural product supply chain, the data about the information of agricultural products is mainly collected by means of manual and bar code. This can easily result in delays, errors and lack of information of the internet of things for agricultural supply chain. And it will make logistics and information flow distorted in the transmission process. It is useful to establish a system that monitors and traces the quality of agricultural materials. The agricultural supply chain management is based on the internet of things which can process the logistics information of every aspect including the production, procurement, storage, transportation and sale.

Application of the angle from the Internet of things, the application of Internet of things technology will also be divided into three stages: the comprehensive development period the typical application demonstration period, growth period, scale. Chinese IOT is still in the typical application demonstration period, the Internet of things will take a long time to develop. At present, the Internet of things technology and application in the back field have been mature, but failed

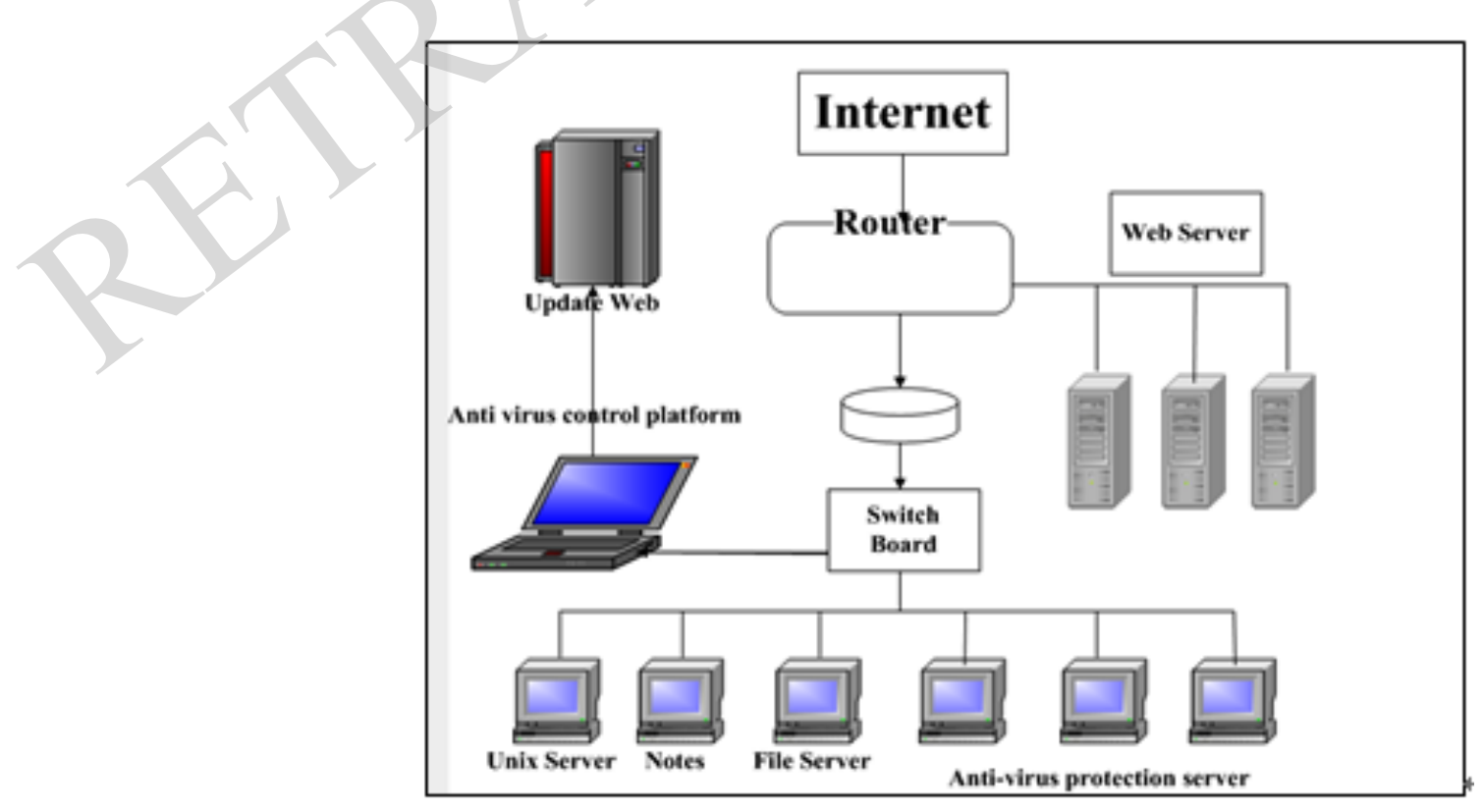

Fig. (2). The architecture system of the internet of things for agricultural supply chain. 


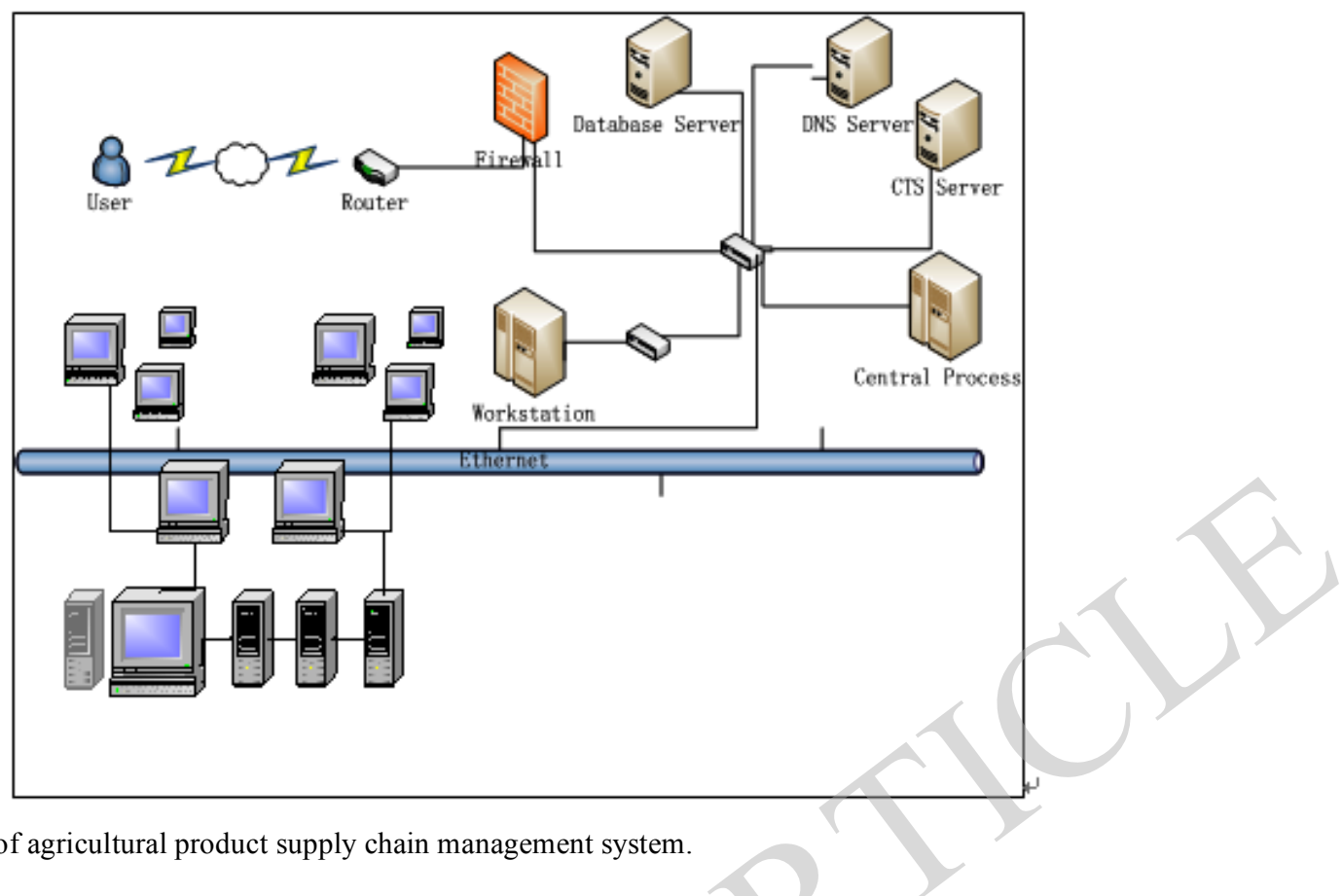

Fig. (3). Network structure of agricultural product supply chain management system.

in the logistics, retail and other fields has been a breakthrough may be due to the industrial chain which is too long, industrial organization is too complex, high in transaction costs, the industry scale is difficult to reduce the problem of limited cost, so that the overall market growth is slow.

\subsection{Analysis of Process in Agricultural Supply Chain}

\section{a) Production stage}

Agricultural products are sent to the farmers mainly through production, transportation, storage, sales and other stages. In the production process of agricultural products, the entire items in product line including raw materials, products, semi-finished products and finished products should be identified and tracked to achieve a balanced and steady production. Each agricultural product is labeled with RFID tag encoded with the EPC.

From the processing plant products shipped after storage, RFID/EPC tag information in fixed locations RFID can be read into the wagon inside the product variety and quantity information. People can order information, once found error, return the working personnel and processing factory communication; if shipment is correct, then classify products. Each batch of agricultural products will be stacked together and it is convenient for storing and linking goods.

\section{b) Transportation stage}

In order to ensure the quality of aquatic products, it reduces the loss of aquatic products, aquatic products must be in transport in low temperature environment, the temperature inside the car with the effective monitoring of the temperature sensor RFID/EPC tags, and is transmitted to the management system of distribution center. The following is distribution of aquatic products distribution center to the seller as an example to illustrate the distribution management business process. For the terminal vendors, through the Internet of things system can facilitate the view goods traffic condi- tion through the ERP system vendors, to understand the transport of goods to some position. At the same time, installing wireless data acquisition system on the vehicles can not only learn the basic information and quantity of the goods, but also detects and prevents the lost and stolen goods during the transportation (Fig. 3).

\section{c) The system function design}

Database about agricultural products should be established and set product code as its key information. It will not only help the enterprises improve storage utilization, reduce inventory and save costs, but will also help the enterprises well aware of the business inventory and will make a scientific and accurate decision during ordering and production.

\section{d) Sale stage}

The application of the internet of things in the stage of agricultural products' sale can be reflected in the statistics, security and validity monitoring forms. Farmers can determine whether the agricultural product is expired according to the production date EPC tags and then judge its quality. When the accident occurred in agricultural products, manufacturers, distributors, or farmers can find the final consumer by traceability system and find the places that occurred problems. This will help form a chain of efficient management and query.

\section{THE ROLE OF THE INTERNET OF THINGS IN THE AGRICULTURAL SUPPLY CHAIN}

\subsection{Data Analysis Method}

The agricultural supply chain based on the technology of the internet of things makes each step of the supply chain improve the transparency greatly. Tag RFID can automatically record the entire supply chain of agricultural products in the flow - from production to final farmers. It can not only greatly reduce the "bullwhip effect", inventory costs and 
labor costs in logistics center, but also improves inventory utilization. Structure parameter is the invariance of the causal relationship between the variables only constant.

The following general structure equation:

$y=A_{y}+\theta \quad x=A_{x}+\tilde{O} \quad z=$ ëì + ín

\subsection{Serve on Agriculture, Rural Areas and Farmers Bet- ter}

The agricultural supply chain based on the technology of the internet of things can guarantee the supply of cultural materials and serve every link of agricultural production well. It will improve the efficiency of agricultural supplies and meet the needs of agricultural products by adopting advanced management concepts, management tools and distribution methods of agricultural products.

Analysis on Internet of things technology adoption drive factors, can make agricultural enterprises to understand what are the key factors affecting the adoption of Internet of things technology, can focus on these factors in the process of technology adoption, make things better, faster to implement in the agricultural products supply chain.

\subsection{Test of Fit Goodness}

The agricultural supply chain based on the technology of the internet of things can promote the large-scale sales of agricultural products and make the services of agricultural technology standardization by using the way of modern 10gistics and marketing. This will improve the efficiency of the supply of agricultural enterprises and service level. At the same time it will enhance the competitiveness of China's agricultural enterprises. When monitor server receives the data stored in the database, it can choose to view the corresponding node temperature or humidity of the historical curve, as shown in Figure 4 for the T01 node temperature curve. Through the analysis of the temperature or the humidity curve, the user can summarize agricultural monitoring field, temperature, and humidity change rule.

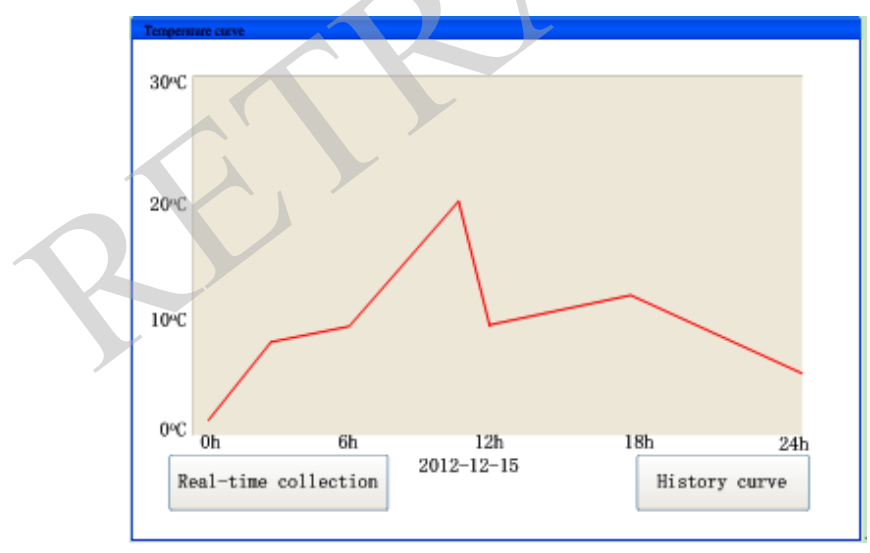

Fig. (4). Temperature and humidity curve.

\section{CONCLUSION}

The numerous factors include support, compatibility, perceived benefit, enterprise scale, top management support, and inter enterprise supply chain trust each other, with technical knowledge, external pressure, the government support has significant positive influence on the adoption of the Internet of things technology, of which the greatest impact is the enterprise scale, the impact is the smallest external pressure; the complexity and cost is the adoption of the Internet of things technology which has significant and negative effects, which has a great impact on the cost of the adoption of the Internet of things technology.

\section{CONFLICT OF INTEREST}

The authors confirm that this article content has no conflict of interest.

\section{ACKNOWLEDGEMENTS}

This work is supported by the Heilongiiang Province philosophy and social sciences planning project"Study on the mechanism and countermeasures of optimizing livestock industry chain in Heilongjiang Province" (No, 14E075)

\section{REFERENCES}

[1] H. Du, J. Wu, and H. Yu, "The research of enterprise's SCM based on internet of things", Logistics Sci-Tech, March, 2011,

[2] A. Hirata, T. Morimoto and Z. Kawasaki, "DOA estimation of ultawideband EM waves with MUSIC and interferometry", IEEE Antennas and Wireless Propagation Letters, vol. 2, no. 1, pp. 190-193, 2003.

[3] E. Grosicki, K. Abed-Meraim and K.Y. Hua, "A weighted linear prediction method for near-field source localization", IEEE Transactions on Signal Processing, vol. 53, no. 10, pp. 3651-3660, 2013.

[4] F. Taga, "Smart Music algorithm for DOA estimation", Electronics Letters, vol. 33, no. 3, pp. 190-191, 1997.

[5] J.X. Wu, T. Wang, Z.Y. Suo, and Z. Bao, "DOA estimation for ULA by spectral Capon rooting method", Electronics Letters, vol. 45 , no. 1 , pp. 84-85, 2012.

[6] J.M. Xin, A. Sane, "Linear prediction approach to direction estimation of cyclostationary signals in multipath environment", IEEE Transactions on Signal Processing, vol. 49, no. 4, pp. 710-720, 2001

[7] H. Li, H. Chen, "Key technology and application prospect of the internet of things", Forum on Science and Technology in China. 2011.

[8] S.C. Kim, I. Song, S. Yoon and S.R. Park, "DOA estimation of angle-perurbed sources for wireless mobile communications", IEICE Trans. Communication, vol. E83-B, no. 11, pp. 2537-2541, 2000.

[9] T.B. Lavate, V.K. Kokate and A.M. Sapkal, "Performance analysis of MUSIC and ESPRIT DOA estimation algorithms for adaptive array smart antenna in mobile communication", International Journal of Computer Networks, vol. 2, no. 3, pp. 152-158, 2010.

[10] Xing Z., Fuxing, "Study on the internet of things in modern agricultural production", Agricultural Technology \& Equipment, August, 2010.

[11] W. Sun, J.L. Bai and K. Wang, "Novel method of ordinal bearing estimation for more sources based on obique projector", Journal of Systems Engineering and Electronics, vol. 20, no. 3, pp. 445-449, 2009.

Received: September 16, 2014

Revised: December 23, 2014

Accepted: December 31, 2014

(C) Zhao and Dong; Licensee Bentham Open.

This is an open access article licensed under the terms of the Creative Commons Attribution Non-Commercial License (http://creativecommons.org/licenses/by-nc/3.0/) which permits unrestricted, non-commercial use, distribution and reproduction in any medium, provided the work is properly cited. 